\title{
A semiótica e princípios da construção teatral
}

Diego MARSICANO (Universidade Ibirapuera - Unib)

RESUMO: Este estudo visa, além da análise semiótica do discurso teatral, a utilização de seus princípios metodológicos a fim de propor uma nova forma de observação às teorias teatrais apresentadas por Constantin Stanislavski. Esta prática pretende lançar uma nova luz à aplicação dos conceitos propostos pelo teórico teatral, e permitir uma maior possibilidade de análise.

PALAVRAS-CHAVE: semiótica; teatro; discurso teatral.

\begin{abstract}
This study aims for analyzing the theatrical discourse according to generative semiotics, as well as to propose a different point of view of Constantin Stanislavski's theories for drama. This work intends to bring a new light to the practice of the concepts proposed by the drama scholar, offering wider means of analyses.
\end{abstract}

KEYWORDS: semiotics; drama; theatrical discourse. 


\section{Introdução}

Apresentamos, aqui, uma análise do discurso teatral, mais especificamente o da tragédia urbana de Nelson Rodrigues Boca de Ouro, por meio do modelo teórico estabelecido pela Semiótica Narrativa e Discursiva, a fim de analisar a proximidade entre as teorias semióticas propostas por Julien Algirdas Greimas e as teorias teatrais de Constantin Stanislavski. O interesse sobre este trabalho surgiu a partir da vontade de aprofundamento do estudo sobre as teorias semióticas e a aplicação delas no discurso teatral.

Teremos então a análise semiótica da obra rodrigueana feita nos diferentes níveis de significação, para enfim, servir de modelo de comparação entre as teorias aqui trabalhadas.

O objetivo maior deste trabalho, além da aplicação das teorias semióticas, é de estabelecer a relação paralela entre as teorias de Greimas e os conceitos pregados por Stanislavski.

\section{Modelo Teórico}

Aqui, basear-nos-emos nas teorias obtidas a partir da obra de Algirdas Julien Greimas, ou seja, o seu Modelo Narrativo e Discursivo.

Greimas toma como base e influência as teorias Estruturalistas de Hjelmslev, o Formalismo Russo de Propp, e a Antropologia de Lévi-Strauss.

Até meados da década de 60, quando Greimas lança Semântica Estrutural, as análises lingüísticas haviam avançado no plano da expressão. Por exemplo, as descobertas que se fizeram no campo da fonologia. Porém, Greimas se interessa e inicia um trabalho que visa uma melhor compreensão e uma análise mais apurada a partir do desbravamento do plano de conteúdo.

Antes de adentrar nas teorias de Greimas cabe relembrar o conceito de planos proposto por Hjelmslev. A língua seria composta por dois planos: o da expressão, que é onde expressamos os signos sejam eles através de textos, desenhos, sinais de trânsito, etc; e o plano de conteúdo, o que entendemos de um signo, o que sabemos sobre ele (o conteúdo é cultural, a partir das experiências individuais).

Para Greimas a significação é um sentido construído socialmente, e se não estivemos familiarizados com os signos não teremos a competência para a identificação do mínimo de sentido. Se um indivíduo não reconhece esse mínimo de sentido ele não tem competência comunicativa. Portanto, Greimas busca se aprofundar no estudo do mecanismo de construção do sentido do discurso. Sabemos então que ele interessar-se-á a respeito do plano de conteúdo a partir do isomorfismo existente entre os planos de expressão e de conteúdo, ou seja, a obrigatoriedade de que o plano de conteúdo é sempre equivalente ao plano de expressão.

Para a semiótica greimasiana a análise deve ser prioritariamente paradigmática. Uma análise sintagmática não será completa se não for feitas inicialmente de forma paradigmática. Para tanto ele se baseia na obra "A Morfologia do Conto" de Vladmir Propp, onde cada personagem, cada ação e a ordem dos acontecimentos têm a sua 
função dentro do conto. Propp analisa os contos de forma sintagmática, e Greimas faz a mesma analise de forma paradigmática.

Seguindo a mesma linha de análise há em Greimas a retomada da teoria de LeviStrauss que diz, assim como Aristóteles, que os mitos são formados pelas ações dos sujeitos, e assim entendemos que essas ações exercem função dentro da narrativa e na criação do mito.

Mas quando citamos ações como pontuais num discurso, não estamos dizendo qualquer ação, mas ações que transformam o sujeito, ações que mudam o estado do sujeito do discurso.

Denis Bertrand, posteriormente à Greimas, priorizando a análise paradigmática retoma a "Morfologia do Conto" da seguinte forma. Ele cria, de forma sintagmática, uma seqüência de acontecimentos da narrativa que valorize a análise paradigmática.

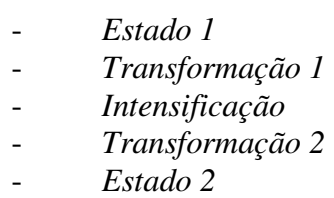

Bertrand une a análise paradigmática proposta por Greimas com a sintagmática de Propp dando valor equivalente aos dois eixos.

Nas estruturas mais profundas do plano de conteúdo a personagem se descaracteriza de sua figurativização, ou seja, o que ela veste, o seu sexo, a cor da pele, seus cabelos, etc, são simplesmente ornamentos (figuras) que pouco importam numa análise de abstração, mas que farão presença quando na análise da manifestação como forma de representação do verificado nos níveis mais abstratos.

Os sujeitos, já descaracterizados de suas figuras, passam a ser chamados de actantes, pois só importam quando agem a fim de modificar seus estados iniciais, que é estar disjunto de seu objeto de valor, para depois estar conjunto com ele, ou vice-versa. Se as ações dos sujeitos de uma narrativa não implicam na transformação de seu estado inicial, estas ações passarão a ser figuras da narrativa e não um fazer modificador.

Assim, teremos o Percurso Gerativo do Sentido que analisa semântica e sintaticamente três níveis de significação: o primeiro com abstração total do discurso: nível fundamental, que observa a relação entre os objetos do discurso; um segundo com menos abstração: nível narrativo, que observa as relações dos objetos com os sujeitos do discurso, ou ainda, a relação entre os sujeitos do discurso; e finalmente o nível mais próximo da manifestação discursiva, nível discursivo, que analisa a relação entre o manifestado no discurso com as observações feitas nos demais níveis.

\section{Do Poder à Morte}

Primeiramente buscaremos estabelecer o eixo, ou melhor, os eixos semânticos fundamentais a partir do qual a narrativa do Boca de Ouro se estrutura. 
Há dois eixos semânticos presentes na obra rodriguiana. Estes dois eixos estão constituídos de forma lógico-semântica e posteriormente constituem um único eixo semântico embasando os conceitos fundamentais da tragédia.

Esses eixos semânticos vão fundamentar a busca do sujeito por objetos de valor, e estão relacionados numa estrutura semântica, constituindo a estrutura elementar de significação do discurso.

Para tanto, teremos o seguinte eixo semântico: o termo conjuntivo /existência/ e seus disjuntivos /vida/ e /morte/ constituindo a estrutura elementar de significação com um valor descritivo.

Assim, como no eixo semântico descritivo, teremos no eixo semântico do nível modal os seguintes semas disjuntivos: /poder/ e /submissão/.

Há na tragédia dois tipos de objeto /poder/. Há o poder estabelecido socialmente e o poder estabelecido pelo dinheiro.Nem sempre o sujeito conjunto com o poder social está em conjunto com poder do dinheiro. No caso do "Boca de Ouro", o anti-herói "Boca" tem o poder no aspecto financeiro, ele possui o poder através do dinheiro, ele compra o que quer. Enquanto a Grã-fina (Maria Luísa) tem o poder estabelecido por sua posição social, ela consegue o que quer por ser reconhecida socialmente, mas não por ter o poder de compra. O anti-herói busca o poder social, pois está em conjunção com o objeto poder financeiro e Maria Luisa busca o poder financeiro. Mas devemos ressaltar que nenhum dos dois quer abrir mão do seu poder, eles buscam agregar poderes para assim aumentar a sua competência perante o outro, já que quem tem mais poder vence.

Temos então dois eixos que se baseiam na estrutura semântico-lógica, e desses constituiremos um eixo único que se estabelecerá como sendo os objetos de busca dos sujeitos da tragédia. Este eixo abrangerá tanto o valor descritivo como o valor modal.

Como a vida é um objeto constituído descritivamente a todos os sujeitos ela não estará como algo a ser buscado, mas coloca-se como um objeto a ser mantido. A morte pode ser colocada como extremo disfórico do quadrado a fim de ser o objeto sancional negativo dado aos sujeitos que buscam manter o objeto de valor e não obtêm sucesso. Em contraposição ao objeto disfórico descritivo /morte/ teremos o objeto eufórico modal /poder/, que constituirá o objeto de busca dos sujeitos da tragédia. E o disfórico /submissão/ que é o estado de quem está em disjunção com o poder. Teremos, enfim, o seguinte quadrado semiótico modal e descritivo para a estrutura do nível fundamental da tragédia Boca de Ouro:

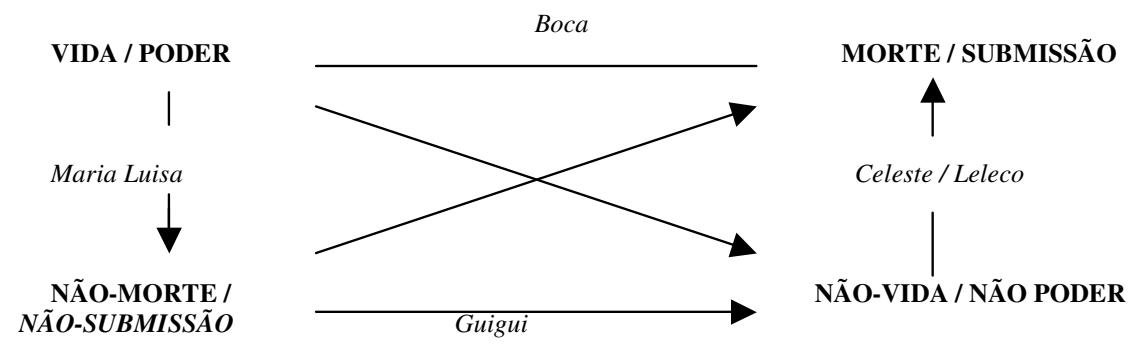


Boca, o anti-herói da história, na busca pelo pode descritivo entra em conjunção com a morte. Passa do estado de poder e vida para o estado de morte, em conjunção com a /morte/. Leleco e Celeste morrem na busca do poder modal, mantendo seu estado disjuntivo com o poder.

Maria Luisa é detentora do poder descritivo e da "não-morte". É ela quem matém seu estado conjuntivo com o objeto de valor.

O texto narra a passagem do personagem/anti-herói Boca que detém o objeto modal /poder/ e descritivo /vida/ que ao entrar em conjunção com a morte perde o seu objeto de valor, ou seja, há uma submissão do poder e da vida para com a morte.

Até este momento, observamos o nível fundamental da tragédia, e agora passaremos a analisar o nível narrativo, ou seja, o plano onde a história começa a tomar corpo. Para tanto devemos a princípio nos perguntar o que faz ou fez com que um sujeito tenha interesse pelo objeto de valor. Com essa pergunta descobrimos quem é o destinador do objeto, quem trouxe à tona o objeto para que o sujeito vá atrás.

No caso desta tragédia o destinador é social, ou seja, não há uma pessoa/sujeito que informe a necessidade ou a ambição para o objeto poder, mas é a sociedade quem impulsiona a ambição do sujeito para a busca do objeto de valor.

A partir daqui temos a narração da história de busca do objeto e da mudança de estado dos sujeitos que o buscam. Um sujeito que busca o objeto está em disjunção com ele, e ao buscá-lo ele promove uma alteração de estado ou ele continua em disjunção com o objeto ou entra em conjunção com ele. Mas além de mudar seu estado conjuntivo ou disjuntivo com o objeto de busca, no caso da tragédia, o sujeito que entra em disjunção com o objeto eufórico /poder/ acaba sendo sancionado negativamente com o objeto disfórico /morte/. Como podemos notar no quadrado semiótico, proposto acima, para a tragédia.

Quando Bertrand propõe essa estrutura ele a coloca como "ancorada na estrutura dos enunciados" e não das ações, porém na análise aqui efetuada valorizaremos as ações transformadoras, e os enunciados só terão relevância quando forem responsáveis por alguma transformação.

Para tanto teremos na obra de Nelson Rodrigues a seguinte estruturação semiótica:

$\begin{array}{ll}\text { Estado 1 - } & \mathrm{S} 1 \cap \mathrm{Ov} \text { (poder modal) } \cap \mathrm{Ov} \text { (vida) } \\ & \mathrm{S} 2 \cup \mathrm{Ov} \text { (poder) } \cap \mathrm{Ov} \text { (vida) } \\ \text { Transformação 1 - } & \mathrm{S} 2-\mathrm{S} 1 \cap \mathrm{Ov} \text { (poder) } \\ \text { Intensificação - } & \mathrm{S} 2 \cup \mathrm{Ov}(\text { vida) } \cup \mathrm{Ov} \text { (poder) } \\ \text { Transformação 2 - } & \mathrm{S} 1-\mathrm{S} 3-\mathrm{S} 1 \cap \mathrm{Ov} \text { (poder descritivo) } \\ \text { Estado 2 - } & \mathrm{S} 1 \cup \mathrm{Ov}(\text { vida) } \cup \mathrm{Ov} \text { (poder) }\end{array}$

No estado inicial temos a apresentação dos dois tipos de sujeitos da narrativa. O primeiro, S1, está em conjunção com o objeto de valor modal /poder/ e, também em conjunção com o objeto de valor descritivo /vida/. Este sujeito é representado pelo actante "Boca de Ouro".

O S2 esta em disjunção com o objeto modal, mas em conjunção com o descritivo. Este sujeito se manifesta em dois actantes: Leleco e Celeste. 
$\mathrm{Na}$ "transformação 1" temos a formação do percurso narrativo do qual o "sujeito 2" busca o objeto de valor do "sujeito 1", ou seja, ele quer entrar em conjunção com o objeto de valor modal /poder/.

Com a primeira transformação teremos o resultado, ou seja, a intensificação desta transformação, que é onde o S2 entra em disjunção com o objeto de valor descritivo /vida/ e também em disjunção com objeto de valor modal /poder/.

Após a intensificação segue a transformação 2, na qual o sujeito S1 que está em conjunção com o objeto de valor /poder/ (valor modal) busca o poder descritivo. Vê na Maria Luisa o meio pelo qual ele pode obter esse objeto de valor.

Nessa busca há a caracterização do estado 2 ou estado final, onde o S1 entra em disjunção com o objeto de valor /vida/ e /poder/.

Há, portanto, um percurso narrativo seqüencial onde observamos que na busca do objeto de valor os sujeitos sofrem uma transformação de estado, e assim constituindo a base narrativa do jogo de transição conjunção/disjunção entre os sujeitos da narrativa e o objeto buscado.

Estas ações ocorridas na história são marcadas por dois tipos de manipulação. Ou o herói oferece o objeto eufórico /poder/ como forma de recompensa, e assim o faz por "tentação", ou ele ameaça o sujeito que o confronta com o objeto disfórico /morte/, fazendo uso da "intimidação".

Boca, freqüentemente, manipula o sujeito por intermédio da intimidação, no qual o sujeito acaba entrando em disjunção com a vida, ou seja, acaba morrendo.

É interessante também notar que, baseando-se na "Morfologia do Conto" de Propp, há na tragédia de Nelson Rodrigues a presença do elemento "objeto mágico" que dá ao herói a competência para a obtenção ou para a manutenção do objeto de valor. No caso do "Boca de Ouro" o herói Boca extrai todos os dentes verdadeiros para colocar dentes de ouro. E assim obtém um objeto mágico que lhe dá a competência para as ações. Há, portanto, uma descaracterização deste herói no momento da perda de seus dentes de ouro, tornando-o um reles mortal como todos os outros.

Por se tratar de um discurso teatral, quando analisamos o nível discursivo, observamos que ele é composto por enunciados de debreagem enunciativas, ou seja, as projeções da enunciação são com a pessoa do "eu", o espaço do "aqui" e o tempo do "agora". Sempre quando lemos uma tragédia constatamos a predominância da projeção do atual, do agora onde os discursos tendem a ser em primeira pessoa.

Ainda temos, no discurso teatral, as marcações de ações das personagens, que aparecem em terceira pessoa, mas com função de primeira pessoa. E assim constitui-se a embreagem, ou seja, suspensão das oposições de pessoa. Mas, predominantemente, o discurso é de debreagem enunciativa.

O interessante na tragédia "Boca de Ouro" é que ela é narrada por Guigui, ou seja, a ex-mulher do herói "Boca de Ouro". Ela narra a mesma história duas vezes. Quando da primeira narração, ela não sabe que "Boca de Ouro" está morto, portanto, magoada por ter sido abandonada por ele, ela conta a história de forma a representar um "Boca de Ouro" mau, que mata por qualquer motivo, que é impiedoso e só pensa em si mesmo.

Já na segunda narração, quando ela descobre que "Boca de Ouro" está morto, ela é mais cautelosa e retrata um "Boca" mais calmo, que somente reage aos ataques a 
ele, e não toma nenhuma atitude a não ser que se faça necessária, ou seja, quando ele é ameaçado. Porém não há mudança no jogo intrínseco de valores do discurso.

Enfim, a história é narrada a partir do jogo enunciativo feito pelo enunciador "Guigui" e pelo enunciatário "Caveirinha". O enunciador produz o seu enunciado, de forma passional, deixando-se levar pela situação relativa em que se encontra, ou seja, o enunciatário manipula o enunciador para obter o enunciado desejado.

$\mathrm{O}$ efeito de sentido das duas formas enunciativas, dadas pela Guigui, reforça o caráter ambivalente de Boca: herói mágico e herói sanguinário, ele é tanto um como outro, variando de acordo com o jogo enunciativo do Narrador. Ambivalência esta que é contaminada pela estrutura da tragédia.

As personagens são complexas e, assim como o Boca, possibilitam ao enunciatário uma interpretação mais humana delas, já que o sujeito tem variações de caráter, reagindo aos estímulos das situações.

\section{A semiótica aplicada à teoria teatral}

Quando iniciamos um curso de teatro somos apresentados a Constantin Stanislavski, que é o teórico teatral russo de maior influência no mundo todo. Suas teorias são utilizadas até hoje como base para a formação de atores e diretores. Dentre vários conceitos apresentados por ele, trataremos de três que, além de constituírem a base para a formação do ator, possuem grandes consonâncias com as proposições da teoria semiótica. São elas: as unidades e objetivos, a ação, e o superobjetivo.

Stanislavski propõe que uma peça de teatro, na preparação para a sua encenação deve ser dividida em unidades menores a fim de facilitar a compreensão e mesmo a sua interpretação, já que isso facilitaria a descoberta dos objetivos das ações. Porém, em sua proposta nada consta de meios para a divisão destas unidades, a não ser que seria mais fácil dividi-las por ações grandiosas.

O que propomos é que esta seja feita a partir das teorizações semióticas, como demonstramos na análise do nível narrativo da tragédia urbana, facilitando, assim, a compreensão e a divisão destas unidades através das teorias de análise do nível narrativo. Porém, a divisão feita na análise da obra Boca de Ouro é a partir de um contexto geral da obra com um todo. Se efetuarmos a análise a fim de dividir a obra em unidades menores, como propõe Stanislavski, deveremos fazê-la de forma paradigmática, ou seja, analisar cena a cena, ou programa a programa, e obter uma divisão de análise a partir das unidades transformadoras.

"Em cena, vocês tem sempre de pôr alguma coisa em ação. A ação, o movimento, é a base da arte que o ator persegue.(...) Em cena é preciso agir, quer exterior, quer interiormente"(STANISLAVSKI,2002:66).

Observemos a importância dada pelo teórico para a ação dos atores. E se utilizarmos de princípios semióticos teremos que as ações são importantes desde que constituam uma transformação do estado inicial do sujeito, ou seja, cada unidade se fará marcar a partir do estudo dos programas e dos percursos narrativos, ou seja, a transformação do sujeito conjunto com o objeto de valor que passa a ser disjunto a ele, 
ou vice e versa, seria uma unidade, a manipulação seria outra, a performance seria outra, a sanção outra, a comunicação entre o destinador e o destinatário outra, e assim por diante. Podemos observar na análise anterior que num dado programa há:

Transformação $1-\mathrm{S} 2-\mathrm{S} 1 \cap \mathrm{Ov}$ (poder)

Aqui podemos subdividir em outras unidades analisando a competência do S2 para a obtenção do objeto de valor do $\mathrm{S} 1$, ou ainda a performance deste programa, ou anteriormente a este, podemos analisar o destinador deste objeto. E assim por diante.

Outros conceitos bastantes tratados por Stanislavski e que complementam o anterior, são o objetivo e o superobjetivo. Eles são o motivo pelo qual a cena ou a peça acontece. O que o sujeito quer? O que ele busca? Para Stanislavski o superobjetivo é imprescindível na execução da obra. "Foi ele quem fez com que a peça fosse escrita; deve, também, ser ele o manancial da criação artística do ator. (STANISLAVSKI,2002:325)

O objetivo tratado em Stanislavski estaria representado na semiótica pelo objeto buscado num dado programa narrativo, seja ele um objeto modal ou um de valor.

Como Stanislavski mesmo propõe, o superobjetivo é a motivação mais intrínseca da peça. Teríamos então que para o superobjetivo haveria o quadrado fundamental do discurso embasando o objeto de valor buscado.

Stanislavski ainda prevê que numa dada unidade o objetivo poderia ser o mesmo do superobjetivo. O que na semiótica teríamos que num dado programa narrativo haveria a possibilidade do objeto de valor buscado ser o objetivo daquela dada unidade ou programa. No caso da tragédia analisada o objeto de valor buscado em todo o percurso é $\mathrm{o}$ /poder/, mas pode haver na história um objeto ou objetos modais que se tornariam o objetivo de um dado programa.

O que deixa interessante esta proposta é o fato de que a descoberta do superobjetivo, segundo Stanislavski, é difícil, só o descobre durante os ensaios ou até mesmo durante a encenação, com a ajuda da reação do público, e algumas vezes nem se descobre. Já com a análise semiótica é possível descobri-lo a partir da análise do nível fundamental através do quadrado semiótico. Facilitando, assim, a montagem da peça e tornando menos possível o erro de leitura.

Enfim, o que propomos são meios de facilitar ao analisador do discurso teatral para a retirada de substratos intrínsecos do discurso a fim de promover uma construção mais elaborada da história e da montagem da peça.

\section{Conclusão}

O objetivo deste trabalho foi possibilitar uma maior apreciação a respeito das propostas teoricas trazidas por Greimas de forma a refletir sobre as proximidades delas com a teoria de Constantin Stanislavski. Durante a realização do mesmo, percebemos que tais teorias só teriam uma funcionalidade se aplicadas a um objeto de estudo adequado de forma a evitar que elas enrigecessem o discurso literário e de confirmar as propostas de equivalência entre os pressupostos semióticos e teatrais.

Assim, a aplicação deles no discurso teatral (Nelson Rodrigues) se configurou como meio de observação da teoria semiótica e exemplificação das consonâncias. 
Esperamos, neste ponto, ter contribuído para o desenvolvimento de uma possível análise do discurso teatral e, ainda, indicado que o trabalho ainda se inicia e indica uma continuidade de nossos estudos, uma vez que a proposta encontra-se em estado de germinação a fim de se tornar algo a ser propriamente aplicado.

\section{REFERÊNCIAS BIBLIOGRÁFICAS}

BARROS, Diana Luz Pessoa, FIORIN, José L. (org).Dialogismo, Polifonia, Intertextualidade. São Paulo: Edusp, 2003.

BERTRAND, Denis.Caminhos da Semiótica Literária; Tradução Grupo CASA. $1^{\mathrm{a}}$ ed. Bauru, SP: EDUSC, 2003.

CARLSON, Marvin.Teorias do Teatr: estudo histórico-crítico, dos gregos à atualidade; Tradução de Gilson César Cardoso de Souza. São Paulo: Fundação Editora da UNESP, 1997.

FIORIN, José Luis.Elementos de Análise do Discurso. São Paulo: Editora Contexto, 2004.

GREIMAS, A.J. e COURTÉS,Joseph. Dicionário de Semiótica. São Paulo: Cultrix, 1983.

RODRIGUES, Nelson. Teatro Completo de Nelson Rodrigues - Tragédias Cariocas I. In: MAGALDI, Sábato (org). Rio de Janeiro: Nova Fronteira.

SÓFOCLES. A Trilogia Tebana; Tradução, introdução e notas de Mario da Gama Kury. Rio de Janeiro:Jorge Zahar Editor,2002.

STANISLAVSKI, Constantin.A Preparação do Ator; Tradução de Pontes de Paula Lima. Rio de Janeiro: Civilização Brasiliense, 2002.

STANISLAVSKI, Constantin.Manual do Ator; Tradução de Jefferson Luis Camargo. São Paulo: Martins Fontes, 1989.

\section{Como citar este artigo:}

MARSICANO, Diego. A semiótica e princípios da construção teatral. Estudos Semióticos, Número 3, São Paulo, 2007. Disponível em <www.fflch.usp.br/dl/semiotica/es>. Acesso em "dia/mês/ano". 